\title{
Elevated serum interferon- $\gamma$ in atopic asthma correlates with increased airways responsiveness and circadian peak expiratory flow variation
}

\author{
N.H.T. ten Hacken*, Y. Oosterhoff*, H.F. Kauffman+, L. Guevarras, T. Satoh», \\ D.J. Tolleruds, D.S. Postma*
}

Elevated serum interferon- $\gamma$ in atopic asthma correlates with increased airways responsiveness and circadian peak expiratory flow variation. N.H.T. ten Hacken, Y. Oosterhoff, H.F. Kauffman, L. Guevarra, T. Satoh, D.J. Tollerud, D.S. Postma. @ERS Journals Ltd 1998.

ABSTRACT: Interleukin (IL)-4, IL-5 and interferon (IFN)- $\gamma$ are thought to play an important role in chronic airway inflammation in asthmatic subjects. Increased airways responsiveness and nocturnal airway obstruction are important clinical manifestations of asthma. The aim of this study was to investigate whether IL-4, IL-5 and IFN- $\gamma$ values are elevated in atopic asthma and correlate with its clinical manifestations.

Serum IL-4, IL-5 and IFN- $\gamma$ levels of 17 atopic asthmatics and eight nonatopic healthy subjects were determined at 16:00 and 04:00 $h$ by a chemiluminescence enzyme-linked immunosorbent assay (ELISA) method. The clinical manifestation of asthma was determined by assessment of the degree of airway obstruction, airways responsiveness to methacholine and severity of nocturnal airway obstruction, defined as the mean circadian (16:00-04:00 h) peak expiratory flow (PEF) variation.

Serum IL-4, IL-5 and IFN- $\gamma$ levels were significantly higher in asthmatic subjects as compared to healthy controls, both at 16:00 and 04:00 $\mathrm{h}$. In asthmatic subjects serum IFN- $\gamma$ at both time points correlated significantly with the provocative concentration of methacholine causing a $20 \%$ fall in forced expiratory volume in one second $(\mathrm{PC20}$,meth) $(\mathrm{rho}=\mathbf{- 0 . 5 5})$ and with the mean 16:00-04:00 $\mathrm{h}$ PEF variation (rho=0.53). In contrast, no relationship was found between the levels of IL-4 and IL-5 and the parameters of clinical manifestation of asthma.

The results suggest that the serum interferon- $\gamma$ level is a reflection of the severity of airway inflammation in atopic asthma. More studies are needed to detect the cellular sources and to clarify the exact roles of interferon- $\gamma$ and other pro-inflammatory cytokines in asthma.

Eur Respir J 1998; 11: 312-316.

Asthma is characterized as a chronic inflammatory disease of the airways. The presence of inflammation is associated with airways hyperresponsiveness to inhaled stimuli and the development of increased nocturnal airways obstruction [1]. Many different inflammatory cells are involved in asthma, including activated T-helper lymphocytes, eosinophils, mast cells and macrophages. These cells can synthesize and release cytokines, which are increasingly recognized to be important in chronic inflammation and play a critical role in orchestrating the inflammatory response. In this respect, emphasis has been laid on an imbalance between type 1 T-helper (Th1) and type 2 T-helper (Th2) cytokines in the development of allergic inflammation. Elevated levels of interleukin (IL)-4, an essential cofactor for immunoglobulin E (IgE) production, and IL-5, responsible for the final differentiation, activation and recruitment of eosinophils [2], have been found in serum of patients with asthma [3-6]. Interferon- $\gamma($ IFN- $\gamma)$ on the other hand inhibits Th2 mediated inflammation in atopic diseases. Both elevated [7, 8] and nonelevated [4,6] serum levels of IFN- $\gamma$ have been reported in asthmatic patients.
Depts of *Pulmonology and +Allergy, University Hospital Groningen, The Netherlands. $\S$ Dept of Environmental and Occupational Health, Graduate School of Public Health University of Pittsburgh, USA.

Correspondence: N.H.T. ten Hacken Dept of Pulmonology

University Hospital Groningen

Postbox 30001

$9700 \mathrm{RB}$, Groningen

The Netherlands

Fax: 31503619320

Keywords: Airways

asthma

responsiveness

serum interferon- $\gamma$

Received: February 181997

Accepted after revision October 251997

This study was partly supported by a grant from the Dutch Asthma Foundation (No.s 89.15 and 92.28)
Since little is known about the direct relationship between cytokine levels and the clinical manifestation of atopic asthma (the degree of airway obstruction, airways responsiveness to methacholine and severity of nocturnal airway obstruction, defined as mean 16:00-04:00 h peak expiratory flow (PEF) variation), we determined the concentrations of IL-4, IL-5 and IFN- $\gamma$ in serum and bronchoalveolar lavage (BAL) fluid from subjects with atopic asthma and healthy controls [1]. The asthmatic subjects participating in this study were selected in order to obtain a wide range of circadian PEF variations, and measurements were performed at 16:00 and 04:00 h.

\section{Materials and methods}

\section{Subjects}

Asthmatic subjects (nonsmokers) were selected on the basis of: 1) a history consistent with the diagnosis of 
asthma; 2) atopy, i.e. positive intracutaneous tests against house-dust mite or two of 12 other tested common aeroallergens, expressed as histamine equivalent wheal size (HEWS) $\geq 0.7$ [9]; 3) forced expiratory volume in one second (FEV1) $>1.5 \mathrm{~L}$ and $>70 \%$ predicted; postbronchodilator FEV1 (salbutamol $400 \mu \mathrm{g}$ using a spacehaler) $>10 \%$; 4) provocative concentration of methacholine bromide causing a $20 \%$ fall in FEV1 (PC20,meth) $\leq 9.8 \mathrm{mg} \cdot \mathrm{mL}^{-1}$; 5) no use of oral corticosteroids within 2 months, inhaled corticosteroids within 4 weeks or cromoglycates within 2 weeks before the study; and 6) no upper respiratory infection(s) within 1 month before the study.

Nonsmoking healthy volunteers had: 1) no history of lung disease or allergy; 2) no atopy, i.e. negative intracutaneous tests against 12 common aeroallergens (HEWS $<0.7$ ); 3) no airways hyperresponsiveness to methacholine ( $<10 \%$ fall in FEV1 after inhalation of $9.8 \mathrm{mg} \cdot \mathrm{mL}^{-1}$ methacholine bromide); and 4) no upper respiratory infection(s) within 1 month before the study.

\section{Study design}

IL-4, IL-5 and IFN- $\gamma$ were analysed in serum and BAL fluid, obtained during a prospective study on nocturnal asthma, published previously [1]. In this study FEV1, blood sampling and bronchoscopy were performed at 16:00 h (or 04:00 h), and repeated 7-14 days later at 04:00 h (or 16:00 h)

Three days before the first investigation, bronchodilators $\left(\beta_{2}\right.$-agonists or ipratropium bromide) were withheld and PEF values were recorded with a mini-Wright peak flow meter at 08:00, 12:00, 16:00, 20:00, 24:00 and 04:00 h. The 16:00-04:00 h PEF variation was defined as: (16:00-04:00 h value)/mean of six daily measurements. The mean 16:00-04:00 h PEF variation was calculated as the average of the 16:00-04:00 h PEF variation measured during 3 days. FEV1 and airways hyperresponsiveness to methacholine ( $\mathrm{PC} 20$,meth), were assessed within 5 days before the first bronchoscopy. FEV1 was measured with a calibrated water-sealed spirometer according to standardized guidelines [10]. Airways responsiveness to doubling concentrations of $0.03-9.8 \mathrm{mg} \cdot \mathrm{mL}^{-1}$ methacholine bromide (Sigma Chemical Co., St. Louis, MO, USA) was measured using a 2 min tidal breathing method adapted from that of Cockcroft et al., as described previously [11].

Thirty minutes before each bronchoscopy, FEV1 measurements were performed and blood samples were taken. Bronchodilator therapy was withheld $8 \mathrm{~h}$ before the pulmonary function tests. The bronchoscopy procedure has been described previously [1]. Briefly, 10 aliquots of 20 $\mathrm{mL}$ sterile phosphate-buffered saline (PBS) at $37^{\circ} \mathrm{C}$ were instilled into the lateral segment of the right middle lobe and recovered by gentle suction $\left(-40 \mathrm{cmH}_{2} \mathrm{O}\right)$ after each aliquot. The BAL fluid was collected in polypropylene cups and immediately placed in ice.

\section{Laboratory techniques}

Processing of BAL fluid. The BAL fluid recovered from the first two $20 \mathrm{~mL}$ aliquots of PBS instilled was processed separately and used for analysis of cytokines. The lavage fluid was filtered through a $100 \mu \mathrm{m}$ pore filter of a venous infusion system (Curapharm, Medica B.V., Hospital Supplies, the Netherlands) to remove mucus, and centrifuged at $400 \times \mathrm{g}$ at $4^{\circ} \mathrm{C}$ for $5 \mathrm{~min}$. The BAL supernatant was decanted from the cell pellet and stored at $-80^{\circ} \mathrm{C}$ until further determination.

Processing of blood samples. Serum was acquired after coagulation of venous blood for $1 \mathrm{~h}$ at room temperature. The supernatant was centrifuged twice for $10 \mathrm{~min}$ at $2000 \times \mathrm{g}$ and stored at $-80^{\circ} \mathrm{C}$ until analysis. Serum total $\mathrm{IgE}$ was determined by a fluoro-immunoassay (Kabi Pharmacia, Woerden, the Netherlands).

Determination of cytokines in serum and BAL fluid. Levels of IL-4, IL- 5 and IFN- $\gamma$ were determined by a chemiluminescence enzyme-linked immunosorbent assay (ELISA) in the laboratory of the Department of Environmental and Occupational Health at the University of Pittsburgh. Ninety six-well opaque microtitre plates (Microlite 1, Dynatech, Chantilly, VA, USA) were coated with $100 \mu \mathrm{L}$ of diluted purified anti-cytokine monoclonal antibody (capture moAb; $\left.1-4 \mu \mathrm{g} \cdot \mathrm{mL}^{-1}\right)$ in $0.1 \mathrm{M}$ sodium bicarbonate $\left(\mathrm{NaHCO}_{3}\right)$ coating buffer. Plates were incubated overnight at $4^{\circ} \mathrm{C}$, generally with gentle shaking, subsequently washed with $300 \mu \mathrm{L} \cdot$ well $^{-1}$ of PBS-Tween and blotted dry. Wells were blocked with $300 \mu \mathrm{L} \cdot w^{-1 l^{-1}}$ of $2.5 \%$ (w/v) bovine serum albumin (BSA)/PBS-Tween and washed with PBS-Tween. Recombinant standards and samples (diluted appropriately in $0.5-1 \%$ BSA/PBS-Tween), were added $\left(100 \mu \mathrm{L} \cdot\right.$ well $\left.^{-1}\right)$, in duplicate or triplicate wells and incubated overnight at $4^{\circ} \mathrm{C}$ with gentle shaking. Plates were then washed with PBS-Tween, and $100 \mu \mathrm{L} \cdot$ well $^{-1}$ biotinylated anticytokine monoclonal antibody (detecting moAb) diluted to appropriate concentration (20-400 $\left.\mathrm{ng} \cdot \mathrm{mL}^{-1}\right)$ with $0.5 \% \mathrm{BSA} /$ PBS-Tween. After incubation at room temperature for $1 \mathrm{~h}$ with gentle shaking, plates were washed with PBS-Tween. Enzyme-labelled avidin or streptavidin in $0.5 \%$ BSA-PBSTween was added at $100 \mu \mathrm{L} \cdot$ well $^{-1}$ and incubated at room temperature for $50 \mathrm{~min}$, with gentle shaking. Plates were then washed and $100 \mu \mathrm{L}$ Lumiphos 530 (Lumigen, Inc., Southfield, MI, USA) were added to each well. After incubating at room temperature for $25 \mathrm{~min}$, light emission was read using a microtitre plate luminometer (ML 1000; Dynatech Laboratories Inc, VA, USA) and the data were analysed using BioCalc Data Analysis Software (Dynatech Laboratories Inc.).

The chemiluminescence ELISA assays have been validated for accuracy and sensitivity using recombinant human cytokines, including World Health Organization (WHO) standard recombinant cytokines. WHO standards included: recombinant Human IFN- $\gamma$ (Catalogue No. Gg23-901530; National Institute of Allergy and Infectious Disease, NIH, Bethesda, MD, USA); recombinant human IL-4 and recombinant human IL-5 (88/656 and 90/586, respectively; National Institute for Biological Standards and Control, Hertfordshire, UK). The assays were extensively tested using media and human serum samples spiked with mixtures of known quantities of recombinant cytokines. Each assay is highly specific for the cytokine of interest, with no detectable cross-reactivity with other cytokines. These studies confirmed the quality assurance data provided by the manufacturers of the monoclonal antibody pairs. 
Using this method, detection levels of IL-4, IL-5 and IFN- $\gamma$ in serum were $5,2.5$ and $2.5 \mathrm{pg} \cdot \mathrm{mL}^{-1}$, respectively. Detection levels of IL-4, IL-5 and IFN- $\gamma$ in BAL-fluid were 10,5 and $<1.25 \mathrm{pg} \cdot \mathrm{mL}^{-1}$, respectively.

\section{Data analysis}

All analyses were performed with the Statistical Products and Service Solutions (SPSS)/PC 5.01 software package (SPSS Inc., Chicago, IL, USA). A p-value of less than 0.05 was considered statistically significant. Undetectable values were set at the lowest detection levels. The MannWhitney U-test was used to compare cytokine levels between groups, and Wilcoxon's matched sign rank test was applied for within-group analysis. Correlations between cytokine concentrations and other parameters were made using Spearman's rank correlation tests.

\section{Results}

Eight healthy volunteers and 17 asthmatic subjects participated in this study. The 12 male and 13 female subjects were equally distributed between the two groups (Chisquared, $\mathrm{p}=0.43$ ). Differences in lung function and other characteristics between the asthmatic and healthy subjects are shown in table 1 .

Serum levels of IL-4, IL-5 and IFN- $\gamma$ were detectable in all asthmatic subjects and in most healthy controls (fig. 1). Median levels of IL-4, IL-5 and IFN- $\gamma$ in the asthmatic subjects were significantly higher than in the healthy controls, both during the day (fig. 1) and night (data not shown). Levels of IL-4 and IL-5 showed a positive correlation with each other in the asthmatic subjects ( $\mathrm{rho}=0.81, \mathrm{p}<0.001)$, as did levels of IL-4 and IFN- $\gamma(\mathrm{rho}=0.62, \mathrm{p}<0.01)$. The correlations between serum cytokines and clinical parameters in the asthmatic patients are shown in table 2. Serum IFN- $\gamma$ at both time points correlated significantly

Table 1. - Characteristics of the participating subjects

\begin{tabular}{lcc}
\hline & Healthy & Asthmatic \\
\hline Subjects n & 8 & 17 \\
Male/Female & $4 / 4$ & $8 / 9$ \\
Age yrs & 24.5 & 22 \\
& $(210-44)$ & $(18-41)$ \\
Positive skin tests & 0 & $6(2-8)$ \\
Total serum IgE IU·L-1 & 39 & 333 \\
& $(7-251)$ & $(105-2000)^{* *}$ \\
Blood eosinophils 16 h & 88 & 264 \\
106cells:L-1 & $(22-297)$ & $(44-605)^{*}$ \\
FEV1 16 h \% pred & 105 & 90 \\
& $(88-125)$ & $(68-114)^{*}$ \\
PC20,meth $\mathrm{mg} \cdot \mathrm{mL}-1$ & $>9.8$ & 0.44 \\
& & $(0.04-1.88)$ \\
16:00-04:00 h PEF variation & 6.9 & 14.9 \\
& $(-0.3-8.0)$ & $(1.7-37.3)^{*}$ \\
\hline
\end{tabular}

Values are expressed as medians, and range in parentheses. *: $\mathrm{p}<0.05 ; * *: \mathrm{p}<0.001$, versus healthy controls. The values of the provocative concentration of methacholine causing a $20 \%$ fall in FEV1 (PC20,meth) were not compared statistically since they were part of the selection criteria. IgE: immunoglobulin E; FEV1: forced expiratory volume in one second; PEF: peak expiratory flow.

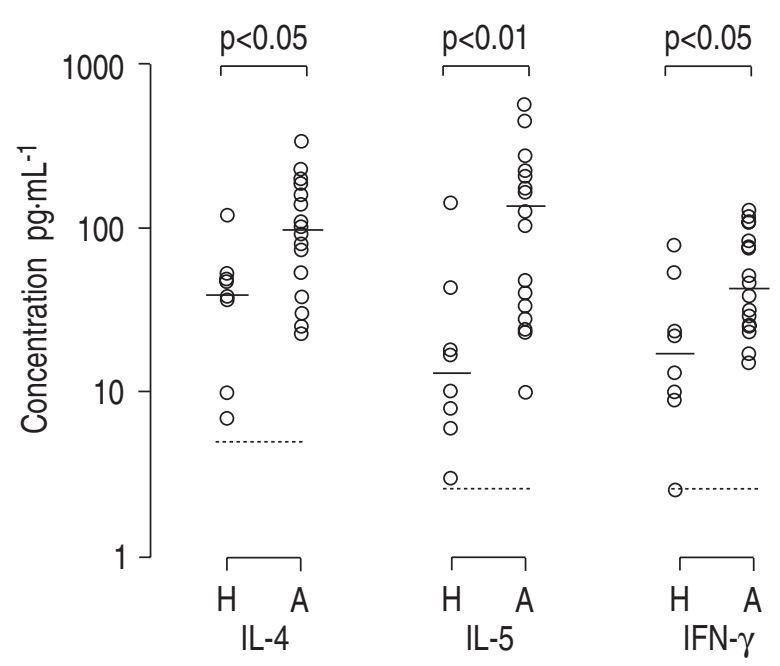

Fig. 1. - Levels of serum interleukin (IL)-4, IL-5 and interferon- $\gamma$ (IFN- $\gamma$ ) of 17 subjects with atopic asthma and eight nonatopic controls, obtained at $16 \mathrm{~h}$. Solid lines represent median cytokine levels. dashed lines represent detection levels. H: healthy controls; A: asthmatic subjects.

with PC20,meth (fig. 2a) and 16:00-04:00 h PEF variation (fig. 2b). Otherwise, no significant correlations were found.

The median IFN- $\gamma$ level in serum of asthmatic patients was significantly higher during the night as compared to the day: 56 (range 16-223) $\mathrm{pg} \cdot \mathrm{mL}^{-1}$ at 04:00 h versus 46 (range $15-128) \mathrm{pg} \cdot \mathrm{mL}^{-1}$ at $16: 00 \mathrm{~h}(\mathrm{p}<0.05)$. Day-night changes of IFN- $\gamma$ in the asthmatic subjects did not correlate with day-night changes in PEF or $\mathrm{FEV} 1 \%$ pred. The median IFN- $\gamma$ levels in healthy subjects were not significantly different between day and night and there were no significant differences between day and night in IL-4 and IL-5 levels in healthy and asthmatic subjects (data not shown).

BAL fluid levels of IL-4, IL-5 and IFN- $\gamma$ were frequently below the level of detection: in the eight healthy volunteers, levels below the detection limit were found in none, four and eight of the subjects, respectively, and six, 12 and 14 of the 17 asthmatic subjects, respectively (16:00 h). Median (range) values of IL-4, IL-5 and IFN- $\gamma$ in the healthy volunteers were: 17.5 (10-71), 6 (5-24) and $<1.25$ $(<1.25) \mathrm{pg} \cdot \mathrm{mL}^{-1}$, respectively $(16: 00 \mathrm{~h})$. Median (range) values of IL-4, IL-5 and IFN- $\gamma$ in the asthmatic subjects were: 14 (10-442), 5 (5-143) and <1.25 (<1.25-0.8) pg. $\mathrm{mL}^{-1}$, respectively $(16: 00 \mathrm{~h})$. Median BAL fluid levels of IL-4, IL-5 and IFN- $\gamma$ were not significantly different between healthy and asthmatic subjects at the different time points,

Table 2. - Correlations between serum cytokines (16:00 h) and important clinical parameters of asthma

\begin{tabular}{lrrc}
\hline & IL-4 & IL-5 & IFN- $\gamma$ \\
\hline Total serum IgE & -0.17 & -0.34 & -0.01 \\
Blood eosinophils & 0.29 & 0.28 & 0.27 \\
FEV1 \% predicted & -0.29 & -0.38 & -0.33 \\
PC20,meth & -0.21 & -0.06 & $-0.55^{*}$ \\
16:00-04:00 h PEF variation & 0.29 & 0.06 & $0.53^{*}$ \\
\hline
\end{tabular}

Values are correlation coefficients (Spearman's rank test). *: $\mathrm{p}<0.05$. Only the $16: 00 \mathrm{~h}$ values are presented because the 04:00 h values were virtually identical. The same correlations were significant. IL: interleukin; IFN- $\gamma$ : interferon- $\gamma$. For further definitions, see legend to table 1. 

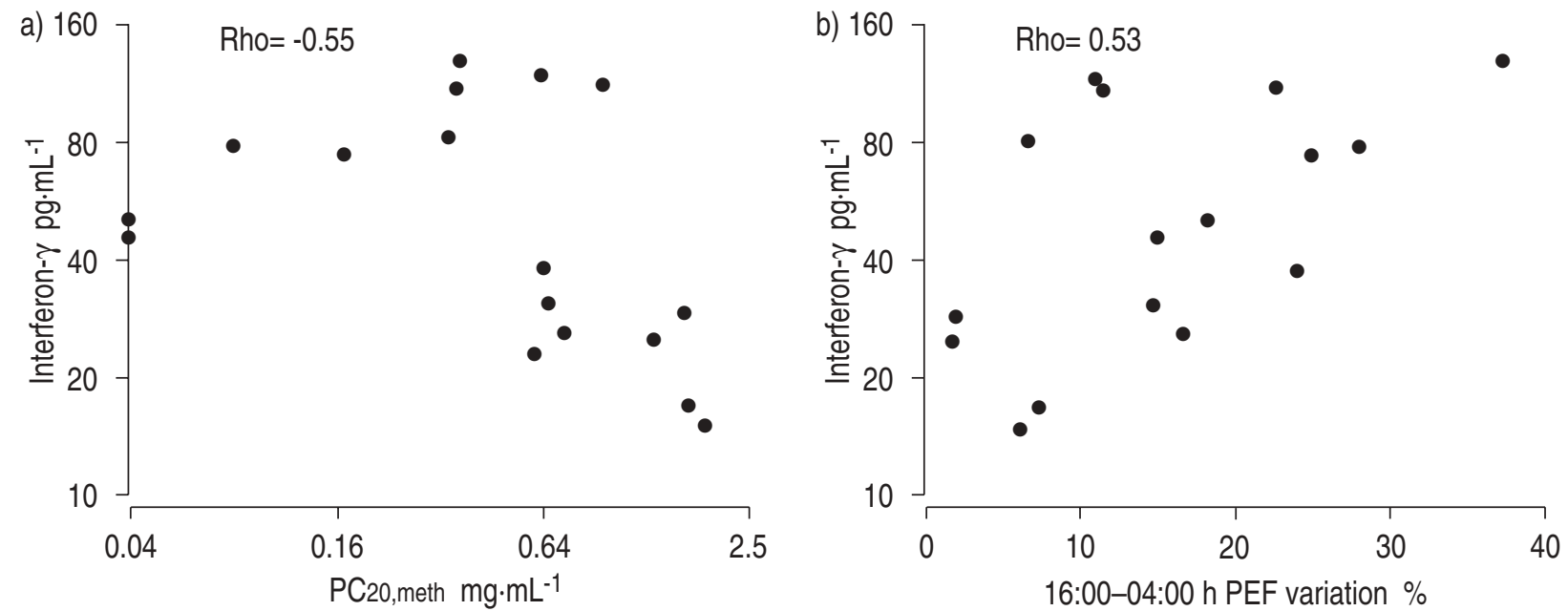

Fig. 2. - Correlation between serum interferon- $\gamma$ levels $\left(\mathrm{pg} \cdot \mathrm{mL}^{-1}\right)$ at 16:00 $\mathrm{h}$ and: a) PC20,meth values; and b) 16:00-04:00 h peak expiratory flow (PEF) variation, in 17 subjects with atopic asthma. For further definition, see legend to table 1.

or between day and night values within the healthy and asthmatic groups. The BAL fluid levels of IL-4, IL-5 and IFN- $\gamma$ did not correlate with the PC20 values, 16:00-04:00 $\mathrm{h} \mathrm{PEF}$ variation or $\mathrm{FEV} 1 \%$ pred.

\section{Discussion}

This study demonstrated that the median levels of serum IL-4, IL-5 and IFN- $\gamma$ were significantly higher in the asthmatic group than in the healthy control group. Moreover, elevated serum levels of IFN- $\gamma$ in subjects with atopic asthma were correlated with an increased airways responsiveness to methacholine and a larger 16:00-04:00 $\mathrm{h}$ PEF variation. In contrast, no relationship was found between serum levels of IL-4 and IL-5 and the parameters of clinical manifestation of asthma. Median levels of IL-4 and IL-5 in BAL fluid were not different between asthmatic and healthy subjects, whereas the levels of IFN- $\gamma$ in BAL fluid were mainly below the level of detection with the method used.

The finding of higher serum IFN- $\gamma$ levels are in line with the results of two other studies. SAITo et al. [8] showed a higher mean plasma concentration of IFN- $\gamma$ in patients with mite-sensitive asthma as compared to healthy controls. In addition, CORRIGAN et al. [7] showed that serum IFN- $\gamma$ levels were elevated in patients with acute severe asthma and normalized upon treatment. Unlike the study of CORRIGAN et al. [7] our patients did not suffer from a viral or bacterial airway infection as a potential cause for increased IFN- $\gamma$ production. The relationships between higher serum IFN- $\gamma$ levels and increased nocturnal airway obstruction and increased airways responsiveness to methacholine rather suggest that the increased serum IFN- $\gamma$ levels reflect an ongoing inflammatory process that determines the clinical manifestations of airway disease in atopic asthma. In ovalbumin-challenged mice it has been found that treatment with antibodies to IFN- $\gamma$ selectively abolished development of airway hyperresponsiveness, whereas antibodies to IL-5 inhibited BAL eosinophilia [12], suggesting that INF- $\gamma$ and IL-5 act on different phenomena. It has been reported that symptom-atic asthma is associated with the production of additional cytokines, including tumour necrosis factor- $\alpha$ (TNF- $\alpha)$, granulocyte/macrophage colony stimulating factor (GM- CSF) and IL-6 [13] in BAL fluid, while the levels of GM- CSF in the bronchial epithelium decrease upon treatment with corticosteroids [14]. Unfortunately, measurements of IFN- $\gamma$ in BAL fluid in the present study were frequently below the level of detection, probably as a consequence of dilution. Nevertheless, the present results suggest that the serum IFN- $\gamma$ level can also be regarded as a reflection of the severity of airway inflammation in atopic asthma.

The higher serum levels of IFN- $\gamma$ in the present asthmatic patients and their positive correlation with serum IL-4 levels apparently do not fit with the hypothesis that Th2 lymphocytes are upregulated and Th1 lymphocytes suppressed in atopic asthma. It could be argued that the Th1/Th2-imbalance is responsible for the development of IgE-mediated inflammation. Once asthma is present, other factors may also contribute to the modulation of the severity of airway inflammation. Furthermore, serum cytokine levels probably do not specifically reflect the secretion by peripheral blood Th1 or Th2 lymphocytes. IFN- $\gamma$ can also be produced by other cell types, including type 0 T-helper (Th0) and CD8 lymphocytes, granulocytes, eosinophils and macrophages, present in the bronchial wall, peri-pheral blood and other body compartments. It has been shown that the in vitro production of IFN- $\gamma$ by peripheral blood mononuclear cells is not increased in patients with asthma $[4,6,15]$. We assume that the increased IFN- $\gamma$ values found in the serum of the present patients originated from cellular sources outside the vascular compartment. Interestingly, KRUG et al. [15] recently demonstrated a higher percentage of IFN- $\gamma$ producing T-cells in the BAL fluid of asthmatic subjects as compared to atopic and nonatopic controls. On the other hand, Ying et al. [16] showed a significantly lower number of CD3 and CD68 positive cells encoding messenger ribonucleic acid (mRNA) for IFN- $\gamma$ in the bronchial biopsies of atopic asthmatics as compared to healthy controls, but no information was presented on production of the protein. Up to now, no attention has been paid to cytokine signals in granulocytes and CD8 positive cells, nor to cytokine signals in the epithelial airway mucosa. This leaves open the possibility of an increased IFN- $\gamma$ produc- 
tion by inflammatory cells in the superficial layer of the bronchial wall.

In contrast to other studies [3, 6], serum IL-4 levels did not correlate with IgE and serum IL-5 did not correlate with blood eosinophils. We have no clear explanation for our negative findings. It can be hypothesized that the indices of IgE-mediated inflammation are obscured by other inflammatory processes that are more related with the clinical manifestation of asthma.

This study also demonstrated higher levels of IFN- $\gamma$ in the serum at night than during the day in the asthmatic patients. The rise of IFN- $\gamma$ levels did not, however, correlate with day-night changes in PEF or FEV1. Thus, no evidence was found to suggest that increased nocturnal airway narrowing in atopic asthma is associated with increased cytokine production at night. This finding is in line with previous observations, showing that an increased nocturnal airway obstruction merely occurs in asthmatic subjects with signs of increased inflammatory cellular activation in the airways at daytime [17].

In conclusion, elevated serum levels of IFN- $\gamma$ in subjects with atopic asthma were correlated with an increased airways responsiveness to methacholine and a larger 16:00-04:00 h peak expiratory flow variation. In contrast, no relationship was found between the levels of interleukin- 4 and interleukin-5 and the parameters of clinical manifestation of asthma. The results suggest that the serum interferon- $\gamma$ level can be regarded as a reflection of the severity of airway inflammation in atopic asthma. Up to now, the origin of serum interferon- $\gamma$ is unclear. More studies are needed to detect the cellular sources and to clarify the exact roles of interferon- $\gamma$ and other pro-inflammatory cytokines in asthma.

\section{References}

1. Oosterhoff Y, Hoogsteden HC, Rutgers B, Kauffman HF, Postma DS. Lymphocyte and macrophage activation in bronchoalveolar lavage fluid in nocturnal asthma. Am J Respir Crit Care Med 1995; 151: 75-81.

2. Kay AB. T lymphocytes and their products in atopic allergy and asthma. Int Arch Allergy Appl Immunol 1991; 94: 189-193.

3. Matsumoto T, Miike T, Yamaguchi K, Murakami M. Kawabe T, Yodoi J. Serum levels of soluble IL-2 receptor, IL-4 and IgE-binding factors in childhood allergic diseases. Clin Exp Immunol 1991; 85: 288-292.

4. Hashimoto S, Amemiya E, Tomita Y, et al. Elevation of soluble IL-2 receptor and IL-4, and nonelevation of IFN-gamma in sera from patients with allergic asthma. Ann Allergy 1993; 71: 455-458.
5. Matsumoto K, Taki F, Miura M, Matsuzaki M, Takagi K. Serum levels of soluble IL-2R, IL-4, and soluble Fc epsilon RII in adult bronchial asthma. Chest 1994; 105: 681686.

6. Tang ML, Coleman J, Kemp AS. Interleukin-4 and interferon-gamma production in atopic and non-atopic children with asthma. Clin Exp Allergy 1995; 25: 515-521.

7. Corrigan CJ, Kay AB. CD4 T-lymphocyte activation in acute severe asthma. Relationship to disease severity and atopic status. Am Rev Respir Dis 1990; 141: 970-977.

8. Saito H, Hayakawa T, Mita H, Yui YS, Shida T. Augmentation of leukotriene $\mathrm{C}_{4}$ production by gamma interferon in leukocytes challenged with an allergen. Int Arch Allergy Appl Immunol 1988; 87: 286-293.

9. Brand PLP, Kerstjens HAM, Kauffman HF, De Monchy JGR, and the Dutch CNSLD Study Group. Interpretation of skin tests to house dust mite and relationship to other allergy parameters in patients with asthma and COPD. $J$ Allergy Clin Immunol 1993; 91: 560-570.

10. Rijcken B, Schouten JP, Weiss ST, Speizer FE, Van der Lende R. The relationship of nonspecific bronchial responsiveness to respiratory symptoms in a random population sample. Am Rev Respir Dis 1987; 136: 62-68.

11. Oosterhoff Y, Koëter GH, De Monchy JGR, Postma DS. Circadian variation in airway responsiveness to methacholine, propranolol and AMP in atopic asthmatic subjects. Am Rev Respir Dis 1993; 147: 351-357.

12. Hessel EM, Van Oosterhout AJM, Van Ark I, et al. Development of airway hyperresponsiveness is dependent on interferon- $\gamma$ and independent of eosinophil infiltration. Am J Respir Cell Mol Biol 1997; 16: 325-334.

13. Broide DH, Lotz M, Cuomo AJ, Coburn DA, Federman EC, Wasserman SI. Cytokines in symptomatic asthma airways. J Allergy Clin Immunol 1992; 89: 958-967.

14. Sousa AR, Poston RN, Lane SJ, Nakhosteen JA, Lee TH. Detection of GM-CSF in asthmatic bronchial epithelium and decrease by inhaled corticosteroids. Am Rev Respir Dis 1993; 147: 1557-1561.

15. Krug N, Madden J, Redington AK, et al. T-cell cytokine profile evaluated at the single cell level in BAL and blood in allergic asthma. Am J Respir Cell Mol Biol 1996; 14: 319-326.

16. Ying S, Durham SR, Corrigan CJB, Hamid Q, Kay AB. Phenotype of cells expressing mRNA for TH2-type (interleukin 4 and interleukin 5) and TH1-type (interleukin 2 and interferon $\gamma$ ) cytokines in bronchoalveolar lavage and bronchial biopsies from atopic asthmatic and normal subjects. Am J Respir Cell Mol Biol 1995; 12: 477-487.

17. Postma DS, Oosterhoff Y, Van Aalderen WMC, Kauffman HF, Wempe JB, Koëter GH. Inflammation in nocturnal asthma? Am J Respir Crit Care Med 1994; 150: 583586. 